\title{
Defining patterns of care in the management of patients with brain metastases in a large Oncology centre: A single-centre retrospective audit of 236 cases.
}

\begin{abstract}
Aims: The role of selected treatments for brain metastases (BM) is well documented; however the prevalence of these is not. We report on the patterns of care in the management of BM in a large Oncology centre.

Materials and methods: We retrospectively audited 236 cases of newly diagnosed BM from January 2016 to December 2017 by looking at 2 years of radiology reports and gathered data on primary site, survival, treatment received, palliative care input and brain metastases related admissions.

Results Eighty-two percent of cases were related to lung, breast and melanoma primaries. Half of patients received a form of treatment with the other half receiving best supportive care. Of these, whole brain radiotherapy (39\%) and stereotactic radiosurgery $(40 \%)$ were the most common treatment modalities. Most common reasons for admissions were headaches, seizures, weakness and confusion.

Conclusion: This is the first study in the UK that gives an in-depth overview of the real world management of brain metastases. We have demonstrated the prevalence of treatment across the spectrum of brain metastases patients. Radiotherapy is the mainstay of treatment in nearly $80 \%$ of cases; however care needs to be taken in ensuring that SRS is offered to those who are suitable.
\end{abstract}

\section{Introduction}

Brain metastases occur in $20-40 \%$ of patients with metastatic cancer (Nathoo, Chahlavi, Barnett, \& Toms, 2005). The last decade has seen significant advances in systematic anti-cancer treatment (SACT) and patients are living longer than ever before. Despite these advances, brain metastases represent a unique challenge as many SACTs do not reliably cross the blood-brain barrier. Historically, patients were managed with whole brain radiotherapy (WBRT) with a role for neurosurgery in selected cases (Mehta et al., 2010). The results of the QUARTZ trial has led to WBRT falling out of favour in the UK for lung cancer patients (Mulvenna et al., 2016) and it's known neurocognitive toxicity has led to concerted efforts to manage brain metastases differently, either with hippocampal sparing WBRT or with stereotactic radiosurgery (SRS) (Gondi et al., 2014; Pinkham, Sanghera, Wall, Dawson, \& Whitfield, 2015).

SRS is as effective as surgery at achieving good local control and is proven to increase overall survival in selected patients (Linskey et al., 2010). Until recently, access to SRS in the UK was limited to only a few sites. In 2016, NHS England commissioned a number of new SRS services meaning that SRS is now more accessible to more patients closer to home ("NHS England " Patients benefiting from advanced brain tumour treatment set to double," n.d.). The wain of WBRT and the widespread availability of SRS has created 
a paradigm shift in the way we manage brain metastases. NHS England mandates that patients suitable for SRS should be discussed at a specialist MDT comprising a Neurosurgeon, a Neuroradiologist and a Clinical Oncologist who specialises in SRS (NHS Commissioning Board Clinical Reference Group for Stereotactic Radiosurgery. Clinical Commissioning Policy: Stereotactic Radiosurgery/Radiotherapy for Cerebral Metastases. (Reference: NHSCB/D05/P/d NHS Commissioning Board), 2013).

Many patients with brain metastases are likely to be unsuitable for aggressive management, however early contact with palliative care has been shown to improve quality of life and potentially survival (Greer et al., 2012; Hearn \& Higginson, 1998; Temel et al., 2010). The role of each treatment modality for brain metastases is well defined but there is no up-to-date information on the frequency of their use in modern UK practice. The aims of this audit were to better understand current practice by identifying: 1) The treatments undertaken for brain metastases across tumour types; 2) If all patients undergoing SRS are discussed at a specialist regional MDT meeting prior to treatment; 3 ) If, based on imaging and available documentation, whether patients are potentially missing the opportunity to be offered SRS.

\section{Material and Methods}

Over a two year period ( $1^{\text {st }}$ January $2016-31^{\text {st }}$ December 2017), adult patients with a new radiologically confirmed diagnosis of brain metastases were identified by retrieving all Magnetic Resonance Imaging (MRI) and Computed Tomography (CT) head scans that contained the words 'metastases', 'metastasis' or 'met' in the scan's contemporaneous report. Only patients with a confirmed primary cancer were included. Primary intracranial tumours and skull vault metastases were excluded, as were patients attending from outside our trust's local catchment area, the latter to best reflect the incidence of treatments such as surgery and SRS in a typical cancer centre as our trust is a regional referral centre for Neurosurgery and SRS.

Information recorded included patient demographics, primary cancer site, status of extracranial disease, date of diagnosis of brain metastases, involvement of the NeuroOncology multidisciplinary team (MDT), treatment recommended, treatment received, number, duration and reasons for hospital admissions and survival (as of the $29^{\text {th }}$ of April 2018).

Patients who underwent SRS, WBRT or surgery were considered to have received a local therapy for their brain metastases. Patients receiving systemic therapy without local therapy are considered as a separate treated group and are identified as 'SACT' below. Patients who did not receive either local or systemic therapy for their brain metastases were identified as best supportive care (BSC).

In the time period of the audit the regional Neuro-Oncology Multi-Disciplinary Team meeting (MDT) was the forum for discussion of all patients considered for SRS or surgical management of brain metastases (amongst other conditions). 


\section{Results}

\section{Demographics}

Out of 2,422 scans, reviewed, there were 236 cases of newly diagnosed brain metastases in the predefined review period. The median age at diagnosis was 65 years (range 30-87). The median survival across all groups was 115 days (range 1-829). There were more females $(58 \%)$ than males (42\%), a difference mainly attributable to the number breast cancers patients with brain metastases (20\%). Patient characteristics and demographics are summarised in Table 1.

Lung cancer represented the most common primary site (49\%), followed by breast $(20 \%)$ and melanoma (13\%). At the time of diagnosis, just under half of all patients $(47 \%)$ had controlled extracranial disease. Median survival varied by primary site with breast carrying the best prognosis (202 days) and lung carrying the worst (95 days). Survival based on primary site is shown in Figure 1. Tumour specific demographics are summarised in Table 3.

\section{Treatments and Therapies}

Half of the cases received some form of local therapy for their brain metastases with $11 \%$ receiving systemic therapy and 39\% receiving best supportive care. There were 127 local therapies delivered to 118 patients. Of these and SRS (40\%) WBRT (39\%) were the most common with surgery $(21 \%)$ the least common intervention. Some patients had more than one local therapy. Local therapy modality varied according to primary tumour site. In breast, WBRT (54\%) was the most common treatment followed by SRS (15\%). In lung and melanoma, this was reversed with SRS (21\% \& 53\% respectively) more commonly used than WBRT (14\% \& 6\% respectively). Patients who received SRS lived the longest; their median survival was not yet reached at assessment, compared to surgery (210 days) and WBRT (202 days). Patients receiving SACT (without any local therapy) had a median survival of 149 days. Treatment and therapy related outcomes are summarised in table 2. Survival based on treatment modality is shown in Figure 2.

Of the $39 \%$ of patients who did not receive any treatment; median survival was 42 days. Of these, $39 \%$ had contact with palliative care services. Amongst patients treated with local therapy, $54 \%$ were seen by palliative care. Of the patients treated with systemic therapy alone, $19 \%$ had contact with palliative services. Contact rates to palliative services by primary site are summarised in Table 4.

\section{MDT Referrals}

Overall $53 \%$ of patients were discussed at the regional Neuro-Oncology MDT. There was an increase of $6 \%$ in referrals from 2016 to 2017, however this varied according to primary site with $63 \%$ of melanoma cases, $53 \%$ of lung cases, $64 \%$ of other cases and $35 \%$ of breast cases discussed. Year on year, melanoma and lung referrals increased (by $51 \%$ \& $9 \%$ respectively) whilst other referrals remained static, however breast referrals dropped by $7 \%$. All patients who had surgery, $87 \%$ of patients who had SRS and $63 \%$ of patients who received WBRT were discussed. Of the 27 patients (37\%) who had WBRT without MDT discussion 21 of those $(75 \%)$ had a breast primary. Ten of the $26(38 \%)$ patients continuing 
or commencing systemic therapies were discussed. Two percent of patients managed with BSC alone were discussed. MDT referral rates are shown in Table 3.

\section{Admissions}

Sixty-nine percent of patients had a brain metastases related admission. There were 305 admissions accounting for 2318 bed days. The first diagnosis of brain metastases occurred as a direct result of an admission in 63 patients (27\%). The median length of stay was 7 days. The most common reasons for admission were seizures (18\%) headaches, $(17 \%)$ confusion (16\%) and weakness (14\%). Patients with lung primaries had the longest median stay (12 days) and the largest number of admissions (50\% of all admissions)

Bed days varied depending on the treatment received. Patients who received SRS had the fewest bed days as a proportion of total follow up days. They had 63 admissions and 491 bed days, which represented 3\% of the total follow up days. Admissions based on treatment are summarised in Table 2, whilst admissions based in primary site are shown in Table 3.

\section{Cases where SRS could have been given}

All cases which received WBRT were reviewed to see if there was potential to offer SRS at the time that their WBRT was given. To be considered as a missed opportunity, the case must have had radiologically suitable disease as recommended by contemporary local guidelines (volume $<20 \mathrm{cc}$ and $<10$ lesions) and the clinical information available must indicate that the patient might be suitable (i.e. prognosis $>6$ months, KPS $>/=70$, controllable ECD). If a case was discussed at MDT prior to WBRT then these were discounted. Based on these criteria we identified seven cases where a patient had WBRT and would have been suitable for SRS. All seven patients had breast primaries.

\section{Discussion}

This audit represents a comprehensive, up to date picture of brain metastases management and outcomes in a large oncology centre; the $4^{\text {th }}$ largest acute trust in the UK. Though our centre is a tertiary referral centre for the region and encompasses a population of 4.5 million in its regional neurosurgical and SRS service, we have purposefully limited the scope of our audit to the secondary care catchment population of about 1 million. This was done to avoid artificially inflating the incidence of brain metastases and to avoid skewing the patterns of treatment in favour of surgery and SRS. A recent analysis of the trusts catchment population determined that it was generally representative of the UK average when broad sociological, demographic and health and wellbeing characteristics of the population are compared to national figures(McCormick et al., 2017). The frequency and demographics of the primary malignancies represented here is broadly similar to other cohort studies (Berghoff et al., 2016).

There are no accurate figures reporting incidence of brain metastases in the UK or indeed internationally. In the USA best estimates suggest that there would be 70,000 new cases per year- giving a crude incidence of 23/100,000 (Landis, Murray, Bolden, \& Wingo, 1998). In our data, 236 patients were diagnosed in a 2 year period. Using the catchment population figure of 1 million this would mean a crude incidence of 12/100,000 per year. 
Over the last decade there have been rapid advances in the systemic management of many cancers including melanoma, breast cancer and lung cancer. These primary sites represented the majority of cases of brain metastases in our case series. In spite of these advances, many SACT drugs do not reliably induce a response in the brain thus creating a need to separately manage brain metastases in some cases (Mehta et al., 2010). It should be noted; such is the rate at which evidence is changing, that a recent single-group phase 2, trial in melanoma patients found that combination immunotherapy had a $57 \%$ response rate in unirradiated brain metastases (Tawbi et al., 2018). Within lung cancer, there is also significant interest in targeted drug therapies in the management brain metastases however current recommendations are that local therapy (SRS or neurosurgery) should be considered as standard of care (Preusser et al., 2018).

For many, brain metastases still represent a poor prognosis (Sperduto et al., 2010). Our figures show that nearly forty percent of the patients newly diagnosed were suitable for best supportive care only. Median survival in this group was short (42 days). The QUARTZ trial, in lung cancer, showed that WBRT impairs quality of life without improving survival (Mulvenna et al., 2016). The median survival in that trial was similar to our best supportive care group therefore we feel that the avoidance of WBRT in this poor prognostic group was correct and would likely only have caused deterioration in quality of life.

In our study, radiotherapy (both SRS \& WBRT) accounted for nearly $80 \%$ of the local treatments. WBRT was used in over a fifth of all patients. WBRT is associated with significant neurocognitive impairment as well as alopecia (Pinkham et al., 2015). Using an IMRT solution to keep hippocampal doses below 9Gy, neurocognitive impairment can be reduced from $30 \%$ to less than $10 \%$, however this is not in routine use in our centre (Gondi et al., 2014). Despite this, WBRT still plays an important role in those who are not suitable for other, more aggressive, therapies. Using lung cancer as an example, only 6 NSCLC lung cancer patients received WBRT which follows the outcome of the QUARTZ trial. Of these, 3 had an EGFR mutation and the other 3 had controlled extracranial disease, with 4 of the 6 living for at least 6 months. This suggests that physicians are using WBRT pragmatically in those cases where a reasonable prognosis is expected rather than blanket use of WBRT.

Of the 36 breast patients who were treated, 26 received WBRT. Only one patient who received WBRT was later treated with SRS. During our review of the WBRT cases we identified 7 who could potentially have been offered SRS instead. This took into account contemporaneous local guidelines regarding suitability for SRS including performance status, radiological appearance and available documentation of clinical information to infer prognosis. Only cases which were not discussed at the neuro-oncology MDT prior to WBRT were considered. All of these cases were breast primaries.

NHS England recommends that cases considered for SRS need to be discussed at a meeting with a Neurosurgeon, Neuroradiologist and a Neuro-oncologist present (NHS Commissioning Board Clinical Reference Group for Stereotactic Radiosurgery. Clinical Commissioning Policy: Stereotactic Radiosurgery/Radiotherapy for Cerebral Metastases. (Reference: NHSCB/D05/P/d NHS Commissioning Board), 2013). With the evolving role SRS plays in brain metastases management it is challenging for physicians to be up to date with rapidly evolving indications. One way to ensure patients are offered an expert opinion on brain metastases management would be to discuss all cases at a specialist MDT. In our study those specialities with highest referral rate to a specialist MDT had the highest rates of 
SRS treatment. In lung and melanoma specialist advice was sought in $53 \%$ and $61 \%$ of cases respectively and, where treatment was recommended, SRS was offered in over $80 \%$ of cases. Conversely, only 35\% of breast cases were discussed and the SRS rate was only $19 \%$ in treated cases. This could have been doubled to $39 \%$ if all breast cases were discussed. Despite NHS guidance that all cases offered SRS are discussed at an appropriate MDT we found that this was the case in only $86 \%$ of cases.

In total, a little over half of all cases were referred for a specialist MDT opinion. There is therefore already a culture of referring brain metastases cases for advice and this is most prevalent in the least common tumour sites with two-thirds of 'other' primaries seeking advice. In our regional Neuro-oncology MDT in 2017 brain metastases represented $17 \%$ of all cases discussed, an average of 9 per week. This two hour MDT discussed an average of 52 cases and presuming the MDT runs to time left 2 minutes and 18 seconds per case.

In the period from January $1^{\text {st }} 2016$ to April 29 2018 , our 236 patients had a cumulative follow-up of 42,221 days. Of these, 166 (70\%) were admitted 305 times for a total of 2318 bed days. This represents about one day of hospitalisation for every 20 days of follow up. The best supportive care group spent the highest proportion of time in hospital (11.8\%) followed by surgery (6.4\%), SACT (5.8\%), WBRT $(5.3 \%)$ and compared to just $3 \%$ for the SRS group. There were 189 elective bed days associated with surgery which accounts for much of the excess over the SRS group and removing these reduces the unplanned bed days to $3.7 \%$ of total follow-up days. The estimated cost of the bed day varies from $£ 306$ for an excess stay bed day to £1609 for an emergency admission. ("Health and social care integration," n.d.) Based on these figures the cost range for admissions is between $£ 709,308$ at the low end and $£ 3,729,662$ at the top. Whilst the true figure will lie between the two, elective admissions in our review were limited only to elective surgical admissions with the remainder relating to unplanned emergency admissions. In France, $A$ recent analysis of the cost of brain metastases in non-small cell lung cancer demonstrated that the cost to health services of managing these patients was $€ 533$ per patient per month more than managing those with metastases elsewhere- a $22 \%$ difference (Girard et al., 2018).

Irrespective of primary site the four most common reasons for admission were seizure, confusion, weakness and headaches. Knowing this, it may be possible to better educate patients on the symptoms and, with proper support, avoid admission. For instance 52 admissions (17\%) were related to headaches: patient education with telephone support from a dedicated nurse specialist may help avoid many of these admissions. Similarly, seizures account for 56 admissions (18\%) but this may be reduced with patient and carer education on seizure management with buccal midazolam and telephone support. A study of Health professionals' perspectives in patients with brain tumours found that increased care co-ordination and improved communication is needed to improve the information needs of this group (Langbecker, Janda, \& Yates, 2013).

Though a high proportion of patients are nominally being managed with best supportive care, there is at present, no pathway for such patients to follow. Most of the contact with the palliative care team as inpatients following an emergency admission in what can be seen as a reactive approach to providing support. It is not clear why the referrals to palliative care services, especially amongst the supportive care group, are so low though it has been shown that the term 'palliative care' rather than 'supportive care' can make it less 
likely for oncologists to refer patients for fear of causing distress (Fadul et al., 2009). Best supportive care, implemented properly and early, in combination with other treatments can lengthen life and provide a better quality of life (Temel et al., 2010). It should be noted that the patients with lung cancer have the highest contact with palliative care services; this coincides with implementation of an enhanced supportive care program for these patients set up in 2016. We anticipate that by implementing an enhanced supportive care pathway for patients with brain metastases we can encourage the early referral of these patients to proactive outpatient based palliative care services.

\section{Limitations}

Though practical, our search strategy of using imaging as a surrogate may have missed patients who had imaging in other centres and then returned for follow-up care in our centre. It is also possible that our search missed some cases of brain metastases in the first place. The incidence we report is therefore likely an underestimation. The retrospective nature of the audit relies on accurate documentation to infer possible treatment options. Though none were identified, there may have been valid reasons why WBRT was chosen over SRS in the patients who potentially missed out.

\section{Conclusion}

This is the first study in the UK that gives an in-depth overview of the real world management of brain metastases. We have demonstrated the prevalence of treatment across the spectrum of brain metastases patients. Radiotherapy is the mainstay of treatment in nearly $80 \%$ of cases; however care needs to be taken in ensuring that SRS is offered to those who are suitable. Patients with brain metastases represent a complex and varied population deserving of specialist input to optimise management.

We propose that the establishment of a dedicated brain metastases service, supported by a dedicated Brain Metastases MDT, in our centre will have a positive impact on some of the issues highlighted in this study. This MDT was established in January 2018 and comprises a Neurosurgeon, Neuroradiologist, Neuro-oncologist, Palliative Care physician and a Brain Metastases Nurse specialist; whose role specifically includes patient education and support. This MDT encourages referral of all patients with brain metastases and aims to provide a comprehensive and individual treatment based on the patients' wishes, with due consideration to their performance status and prognosis.

We aim to re-audit patient outcomes and treatment after a full year of the establishment of the MDT to ensure all patients offered SRS are discussed at our MDT, to assess impact of the MDT on admissions and equity of access to specialist advice, including improved utilisation of palliative care services by implementing an enhanced supportive care model in those who are identified as best supportive care at MDT. 


\section{References}

Berghoff, A. S., Schur, S., Füreder, L. M., Gatterbauer, B., Dieckmann, K., Widhalm, G., ... Preusser@, M. (2016). Descriptive statistical analysis of a real life cohort of 2419 patients with brain metastases of solid cancers. ESMO Open, 1, 24. https://doi.org/10.1136/esmoopen-2015

Fadul, N., Elsayem, A., Palmer, J. L., Del Fabbro, E., Swint, K., Li, Z., ... Bruera, E. (2009). Supportive versus palliative care: What's in a name? Cancer, 115(9), 2013-2021. https://doi.org/10.1002/cncr.24206

Girard, N., Cozzone, D., de Leotoing, L., Tournier, C., Vainchtock, A., Tehard, B., \& Cortot, A. B. (2018). Extra cost of brain metastases (BM) in patients with non-squamous nonsmall cell lung cancer (NSCLC): a French national hospital database analysis. ESMO Open, 3(6), e000414. https://doi.org/10.1136/esmoopen-2018-000414

Gondi, V., Pugh, S. L., Tome, W. A., Caine, C., Corn, B., Kanner, A., .. Mehta, M. P. (2014). Preservation of memory with conformal avoidance of the hippocampal neural stem-cell compartment during whole-brain radiotherapy for brain metastases (RTOG 0933): a phase II multi-institutional trial. Journal of Clinical Oncology: Official Journal of the American Society of Clinical Oncology, 32(34), 3810-3816. https://doi.org/10.1200/JCO.2014.57.2909

Greer, J. A., Pirl, W. F., Jackson, V. A., Muzikansky, A., Lennes, I. T., Heist, R. S., .. Temel, J. S. (2012). Effect of early palliative care on chemotherapy use and end-of-life care in patients with metastatic non-small-cell lung cancer. Journal of Clinical Oncology: Official Journal of the American Society of Clinical Oncology, 30(4), 394-400. https://doi.org/10.1200/JCO.2011.35.7996

Health and social care integration. (n.d.). Retrieved August 16, 2018, from https://www.nao.org.uk/wp-content/uploads/2017/02/Health-and-social-careintegration.pdf

Hearn, J., \& Higginson, I. J. (1998). Do specialist palliative care teams improve outcomes for cancer patients? A systematic literature review. Palliative Medicine, 12(5), 317-332. https://doi.org/10.1191/026921698676226729

Landis, S., Murray, T., Bolden, S., \& Wingo, P. (1998). Cancer Statistics, 1998. CA: A Cancer Journal for Clinicians, 48(1), 6-29. Retrieved from https://onlinelibrary.wiley.com/doi/pdf/10.3322/canjclin.48.1.6

Langbecker, D., Janda, M., \& Yates, P. (2013). Health professionals' perspectives on information provision for patients with brain tumours and their families. European Journal of Cancer Care, 22, 179-187. https://doi.org/10.1111/ecc.12011

Linskey, M. E., Andrews, D. W., Asher, A. L., Burri, S. H., Kondziolka, D., Robinson, P. D., ... Kalkanis, S. N. (2010). The role of stereotactic radiosurgery in the management of patients with newly diagnosed brain metastases: a systematic review and evidencebased clinical practice guideline. Journal of Neuro-Oncology, 96(1), 45-68. https://doi.org/10.1007/s11060-009-0073-4

McCormick, K., Aderson, S., Kightley, L., Hall, J., Bates, I., Sinclair, J., \& Crouch, N. (2017). Joint strategic needs assessment; The People of Nottinghamshire (2017). Retrieved January 14, 2019, from https://www.nottinghamshireinsight.org.uk/researchareas/jsna/summaries-and-overviews/the-people-of-nottinghamshire-2017/ 
Mehta, M. P., Paleologos, N. A., Mikkelsen, T., Robinson, P. D., Ammirati, M., Andrews, D. W., ... Kalkanis, S. N. (2010). The role of chemotherapy in the management of newly diagnosed brain metastases: a systematic review and evidence-based clinical practice guideline. Journal of Neuro-Oncology, 96(1), 71-83. https://doi.org/10.1007/s11060009-0062-7

Mulvenna, P., Nankivell, M., Barton, R., Faivre-Finn, C., Wilson, P., Mccoll, E., ... Langley, R. E. (2016). Dexamethasone and supportive care with or without whole brain radiotherapy in treating patients with non-small cell lung cancer with brain metastases unsuitable for resection or stereotactic radiotherapy (QUARTZ): results from a phase 3, non-inferiority, randomised trial. The Lancet, 388, 2004-2014. https://doi.org/10.1016/S0140-6736(16)30825-X

Nathoo, N., Chahlavi, A., Barnett, G. H., \& Toms, S. A. (2005). Pathobiology of brain metastases. J Clin Pathol, 58, 237-242. https://doi.org/10.1136/jcp.2003.013623

NHS Commissioning Board Clinical Reference Group for Stereotactic Radiosurgery. Clinical Commissioning Policy: Stereotactic Radiosurgery/Radiotherapy for Cerebral Metastases. (Reference: NHSCB/D05/P/d NHS Commissioning Board). (2013). Retrieved from https://www.england.nhs.uk/wp-content/uploads/2013/04/d05-p-d.pdf

NHS England » Patients benefiting from advanced brain tumour treatment set to double. (n.d.). Retrieved July 25, 2018, from https://www.england.nhs.uk/2016/06/brain-tumourtreatment/

Pinkham, M. B., Sanghera, P., Wall, G. K., Dawson, B. D., \& Whitfield, G. A. (2015). Neurocognitive Effects Following Cranial Irradiation for Brain Metastases. Clinical Oncology, 27(11), 630-639. https://doi.org/10.1016/J.CLON.2015.06.005

Preusser, M., Winkler, F., Valiente, M., Manegold, C., Moyal, E., Widhalm, G., ... Zielinski, C. (2018). Recent advances in the biology and treatment of brain metastases of nonsmall cell lung cancer: summary of a multidisciplinary roundtable discussion. ESMO Open, 3(1), e000262. https://doi.org/10.1136/esmoopen-2017-000262

Sperduto, P. W., Chao, S. T., Sneed, P. K., Luo, X., Suh, J., Roberge, D., ... Mehta, M. (2010). DIAGNOSIS-SPECIFIC PROGNOSTIC FACTORS, INDEXES, AND TREATMENT OUTCOMES FOR PATIENTS WITH NEWLY DIAGNOSED BRAIN METASTASES: A MULTI-INSTITUTIONAL ANALYSIS OF 4,259 PATIENTS. International Journal of Radiation Oncology ${ }^{*}$ Biology ${ }^{\star}$ Physics, 77(3), 655-661. https://doi.org/10.1016/j.jirobp.2009.08.025

Tawbi, H. A., Forsyth, P. A., Algazi, A., Hamid, O., Hodi, F. S., Moschos, S. J., ... Margolin, K. (2018). Combined Nivolumab and Ipilimumab in Melanoma Metastatic to the Brain. New England Journal of Medicine, 379(8). https://doi.org/10.1056/NEJMoa1805453

Temel, J. S., Greer, J. A., Muzikansky, A., Gallagher, E. R., Admane, S., Jackson, V. A., ... Lynch, T. J. (2010). Early Palliative Care for Patients with Metastatic Non-Small-Cell Lung Cancer. New England Journal of Medicine, 363(8), 733-742. https://doi.org/10.1056/NEJMoa1000678

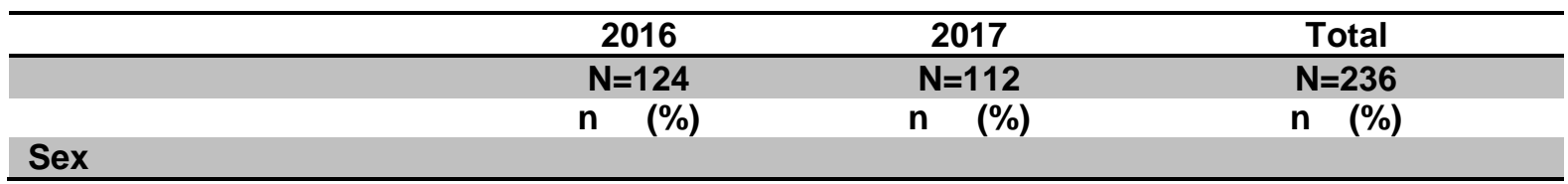




\begin{tabular}{|c|c|c|c|}
\hline $\begin{array}{ll}\text { - } & \text { Female } \\
\text { - } & \text { Male }\end{array}$ & $\begin{array}{l}63(51) \\
61(49)\end{array}$ & $\begin{array}{l}74(66) \\
38(34)\end{array}$ & $\begin{array}{l}137(58) \\
99(42)\end{array}$ \\
\hline Age: Mean (range) & $65(30-90)$ & $65(33-84)$ & $65(30-90)$ \\
\hline \multicolumn{4}{|l|}{ Primary } \\
\hline $\begin{array}{l}\text { - } \text { Breast } \\
\text { - Lung } \\
\text { - } \text { Othelanoma }\end{array}$ & $\begin{array}{l}23(18) \\
57(46) \\
17(14) \\
27(22)\end{array}$ & $\begin{array}{l}25(22) \\
59(53) \\
13(12) \\
15(13)\end{array}$ & $\begin{array}{ll}48 & (20) \\
116 & (49) \\
30 & (13) \\
42 & (18)\end{array}$ \\
\hline ECD controlled & $55(44)$ & $57(51)$ & $112(47)$ \\
\hline $\begin{array}{l}\text { Patients receiving local } \\
\text { Therapy }\end{array}$ & $58(47)$ & $60(53)$ & $118(50)$ \\
\hline $\begin{array}{l}\text { Total local } \\
\text { Treatments* }\end{array}$ & $62(49)$ & $65(51)$ & $127(100)$ \\
\hline - WBRT & $19(34)$ & $30(45)$ & $49(39)$ \\
\hline - $\quad$ SRS & $28(42)$ & $23(37)$ & $51(40)$ \\
\hline - Surgery & $15(24)$ & $12(18)$ & $27(21)$ \\
\hline SACT & $12(10)$ & $14(12)$ & $26(10)$ \\
\hline BSC & $54(43)$ & $39(35)$ & $92(39)$ \\
\hline MDT Discussion & $62(50)$ & $63(56)$ & 125/236 (53) \\
\hline \multicolumn{4}{|l|}{$\begin{array}{l}\text { MDT Discussion by } \\
\text { primary site }\end{array}$} \\
\hline - Breast & 9/23 (39) & $8 / 25 \quad(32)$ & $17 / 48$ \\
\hline - Lung & $28 / 57$ (49) & $34 / 59(58)$ & $62 / 116 \quad(53)$ \\
\hline - Melanoma & $7 / 17 \quad(41)$ & $12 / 13 \quad(92)$ & $19 / 30 \quad(63)$ \\
\hline - Other & $18 / 27$ (67) & $9 / 15 \quad(60)$ & $27 / 42 \quad(64)$ \\
\hline
\end{tabular}

Table 1-demographics Abbreviations: $\mathrm{ECD}=$ Extra cranial disease, MDT= multidisciplinary team, SACT= Systemic Anticancer therapy, BSC= best supportive care, WBRT= Whole Brain Radiotherapy

${ }^{*}$ Number of local treatments exceeds patient number as some received more than one local treatment

Table 2: Treatment Related Outcome

\begin{tabular}{llllll}
\hline & SRS & WBRT & Surgery & SACT & BSC \\
\hline Number & 51 & 49 & 27 & 26 & 92 \\
Median Survival & NR & 202 & 210 & 149 & 42 \\
Days of Follow up & 16,107 & 11,111 & 7,218 & 4,355 & 5,703 \\
Admissions & 63 & 80 & 67 & 33 & 80 \\
Bed Days & 491 & 584 & 459 & 225 & 674 \\
Bed days: Follow up & $3 \%$ & $5.3 \%$ & $6.4 \%$ & $5.9 \%$ & $11.8 \%$
\end{tabular}

Abbreviations: NR=Not reached, SRS= Stereotactic Radiosurgery, WBRT= Whole Brain Radiotherapy SACT= Systemic Anticancer therapy, BSC=Best supportive care

Table 3- Tumour specific demographics

\begin{tabular}{|c|c|c|c|c|c|}
\hline & $\begin{array}{l}\text { Breast } \\
N=48\end{array}$ & $\begin{array}{l}\text { Melanoma } \\
\mathbf{N}=30\end{array}$ & $\begin{array}{l}\text { Lung } \\
\mathrm{N}=116\end{array}$ & $\begin{array}{l}\text { Other } \\
N=42\end{array}$ & $\begin{array}{l}\text { Total } \\
\mathrm{N}=236\end{array}$ \\
\hline $\begin{array}{l}\text { Median Age } \\
\text { (Range) }\end{array}$ & $\begin{array}{l}54 \text { years } \\
(30-87)\end{array}$ & $\begin{array}{l}70 \text { years } \\
(33-84)\end{array}$ & $\begin{array}{l}67 \text { years } \\
(38-86)\end{array}$ & $\begin{array}{l}65 \text { years } \\
(40-70)\end{array}$ & $\begin{array}{l}65 \text { years } \\
(30-87)\end{array}$ \\
\hline $\begin{array}{ll}\text { - } & \text { Male } \\
\text { - } & \text { Female }\end{array}$ & $\begin{array}{l}1(2 \%) \\
47(98 \%)\end{array}$ & $\begin{array}{l}18(60 \%) \\
12(40 \%)\end{array}$ & $\begin{array}{l}57(49 \%) \\
59(51 \%)\end{array}$ & $\begin{array}{l}23(55 \%) \\
19(45 \%)\end{array}$ & $\begin{array}{l}99(42 \%) \\
137(58 \%)\end{array}$ \\
\hline Median Survival & 202 days & 174 days & 95 days & 86 days & 115 days \\
\hline
\end{tabular}




\begin{tabular}{|c|c|c|c|c|c|}
\hline (Range) & $(5-737)$ & $(12-564)$ & $(1-829)$ & $(2-720)$ & $(1-829)$ \\
\hline ECD Control & $27 / 48$ (56\%) & $23 / 30(77 \%)$ & $37 / 116(32 \%)$ & $25 / 42$ (61\%) & $112 / 236(47 \%)$ \\
\hline MDT referral & $17 / 48(35 \%)$ & $19 / 30(63 \%)$ & $61 / 116(52 \%)$ & $27 / 42(66 \%)$ & $125 / 236(53 \%)$ \\
\hline \multicolumn{6}{|l|}{ Treatment: } \\
\hline - $\mathrm{SRS}$ & $7 / 48$ (15\%) & $15 / 30(50 \%)$ & $21 / 116(18 \%)$ & $8 / 42$ (19\%) & $51 / 236(22 \%)$ \\
\hline - WBRT & $26 / 48(54 \%)$ & $2 / 30(6 \%)$ & $16 / 116(14 \%)$ & $5 / 42(12 \%)$ & $49 / 236(21 \%)$ \\
\hline - Surgery & $4 / 48 \quad(8 \%)$ & $3 / 30(10 \%)$ & $11 / 116(9 \%)$ & $9 / 42(21 \%)$ & $27 / 236(11 \%)$ \\
\hline - SACT & $2 / 48(4 \%)$ & $7 / 30(23 \%)$ & $15 / 116(13 \%)$ & $2 / 42(5 \%)$ & $26 / 236(11 \%)$ \\
\hline - $\mathrm{BSC}$ & $11 / 48(23 \%)$ & $5 / 30(17 \%)$ & $57 / 116(49 \%)$ & $19 / 42(45 \%)$ & $92 / 236$ (39\%) \\
\hline Admitted & $36(75 \%)$ & 17 (56\%) & 81 (70\%) & 30 (71\%) & 164 (69\%) \\
\hline $\begin{array}{l}\text { Number of } \\
\text { admissions }\end{array}$ & $\mathrm{N}=61$ & $\mathrm{~N}=34$ & $\mathrm{~N}=152$ & $N=58$ & $\mathrm{~N}=305$ \\
\hline \multicolumn{6}{|l|}{ Symptom } \\
\hline - Seizure & 9/61 (15\%) & $5 / 34(15 \%)$ & $33 / 152(22 \%)$ & 9/58 (15\%) & $56 / 305(18 \%)$ \\
\hline - Headache & $15 / 61(24 \%)$ & $5 / 34(15 \%)$ & $19 / 152(12 \%)$ & $13 / 58(22 \%)$ & $52 / 305(17 \%)$ \\
\hline - Weakness & $8 / 61(13 \%)$ & $6 / 34(18 \%)$ & $22 / 152(14 \%)$ & $6 / 58(10 \%)$ & $42 / 305(14 \%)$ \\
\hline - Confusion & 11/61 18\%) & $8 / 34(23 \%)$ & $20 / 152(13 \%)$ & $9 / 58(15 \%)$ & 48/305 (16\%) \\
\hline - Other & $21 / 61(34 \%)$ & $10 / 34(29 \%)$ & $62 / 152(41 \%)$ & $21 / 58(36 \%)$ & $114 / 305(37 \%)$ \\
\hline Total bed days & 457 & 216 & 1040 & 605 & 2318 \\
\hline Median bed days & 10 & 5 & 12 & 10 & 7 \\
\hline
\end{tabular}

Abbreviations: $E C D=$ Extra cranial disease, $S A C T=$ Systemic Anticancer therapy, BSC= best supportive care, WBRT= Whole Brain Radiotherapy

Table 4: Palliative care team contact by site

\begin{tabular}{|c|c|c|c|c|c|}
\hline & $\begin{array}{l}\text { Breast } \\
N=48\end{array}$ & $\begin{array}{l}\text { Melanoma } \\
\mathrm{N}=\mathbf{3 0}\end{array}$ & $\begin{array}{l}\text { Lung } \\
N=116\end{array}$ & $\begin{array}{l}\text { Other } \\
N=42\end{array}$ & $\begin{array}{l}\text { Total } \\
\mathrm{N}=236\end{array}$ \\
\hline $\begin{array}{l}\text { Palliative care } \\
\text { contact }\end{array}$ & $27 / 48(56 \%)$ & $15 / 30(50 \%)$ & $77 / 116(66 \%)$ & $18 / 42(43 \%)$ & $137 / 236(58 \%)$ \\
\hline $\begin{array}{l}\text { Palliative } \\
\text { contact with } \\
\text { local therapy }\end{array}$ & 18/35 (51) & 9/18 (50\%) & 28/44 (64\%) & 9/21 (43\%) & $64 / 118(54 \%)$ \\
\hline $\begin{array}{l}\text { Palliative } \\
\text { contact SACT }\end{array}$ & $1 / 2(50 \%)$ & $0 / 7(0 \%)$ & $3 / 15(20 \%)$ & $1 / 2(50 \%)$ & $5 / 26(19 \%)$ \\
\hline $\begin{array}{l}\text { Palliative care } \\
\text { contact in BSC }\end{array}$ & 4/11 (36\%) & $1 / 5$ (20\%) & $23 / 57(40 \%)$ & $8 / 19(42 \%)$ & 36/92 (39\%) \\
\hline
\end{tabular}




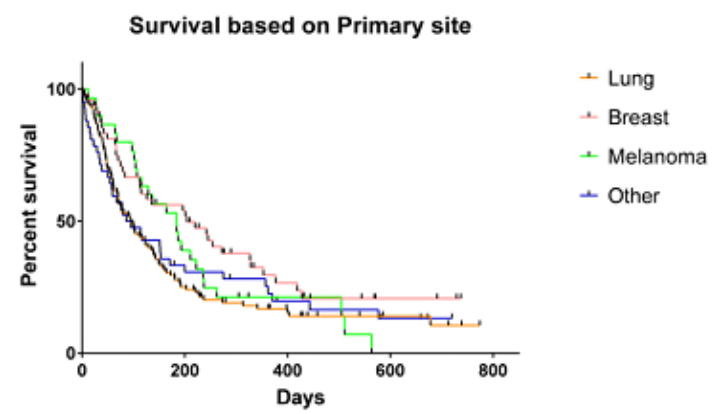

Figure 1: Survival by Primary Site

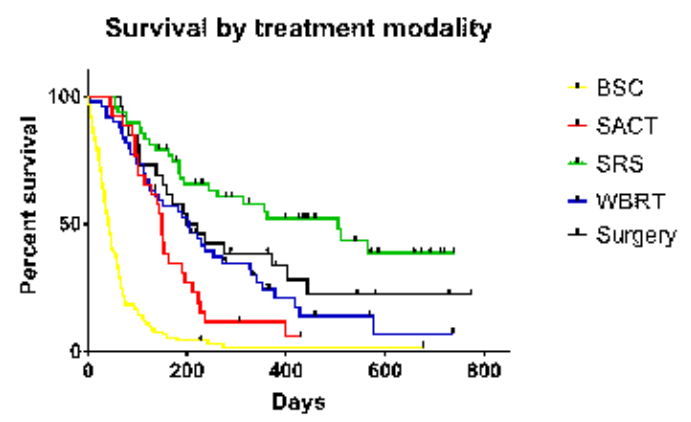

Figure 2: Survival by treatment modal ity

Abbreviations: BSC= Best supportive care, SACT= Systemic Anticancer therapy, SR S= Stereotactic Radio surgery, 